\title{
Molecular Docking and Physicochemical Analysis of the Active Compounds of Soursop (Annona muricata Linn) for an Anti-Breast Cancer Agent
}

\author{
Tony Sumaryada ${ }^{1, *(\mathbb{D})}$, Andam Sofi Astarina ${ }^{1}$, Laksmi Ambarsari ${ }^{2}$ \\ 1 Computational Biophysics and Molecular Modeling Research Group (CBMoRG), Department of Physics, IPB University, \\ Jalan Meranti Kampus IPB Dramaga Bogor 16680, Indonesia \\ 2 Department of Biochemistry, IPB University, Kampus IPB Dramaga Bogor 16680, Indonesia \\ * Correspondence: tsumaryada@apps.ipb.ac.id;
}

Scopus Author ID 55872955200

Received: 28.10.2020; Revised: 1.12.2020; Accepted: 3.12.2020; Published: 11.12.2020

\begin{abstract}
Breast cancer cases continue to increase every year. One plant that potentially has the antibreast-cancer activity is soursop. Some compounds in soursop (Annona muricata Linn) have been reported to inhibit COX-2 enzyme (PDB code: 3LN1) activity. However, each of these test compounds' inhibition potential has not been known really well and still needs to be explored. In this research, the molecular docking simulation and the physicochemical and pharmacochemical descriptor analysis (using Swiss ADME server) were used to explore the potential of compounds contained in soursop as a COX-2 inhibitor for an anti-breast cancer agent. The results have shown that xylopine can inhibit the COX-2 enzyme activity with a binding energy of $-11.9 \mathrm{kcal} / \mathrm{mol}$. Its physicochemical and pharmacochemical descriptors are still within the range of oral drug bioavailability. Molecular interaction analysis has also revealed Val335, Leu338, Ser339, Trp373, Phe504, Val509, Gly512, Ala513, Ser516 amino acids always appear in ligand-COX-2 interaction and predicted to play an important role in the COX-2 inhibition mechanism.
\end{abstract}

Keywords: COX-2; breast cancer; soursop; molecular docking; herbal.

(C) 2020 by the authors. This article is an open-access article distributed under the terms and conditions of the Creative Commons Attribution (CC BY) license (https://creativecommons.org/licenses/by/4.0/).

\section{Introduction}

Breast cancer is the most common cancer in women and affecting about one in ten women worldwide. Based on data by the World Health Organization (WHO) in 2019 [1], the number of deaths from breast cancer cases worldwide has reached 2,088,849 (11.6\%). Based on these data, the number of cancer patients in developing countries is bigger than in developed countries, by around 58\%. According to data from the Globocan, the number of breast cancer cases in Indonesia in 2018 is 13,380 (13.1\%) [2].

Cyclooxygenase-2 (COX-2) is an enzyme that causes cancer by catalyzing prostaglandins' biosynthesis from arachidonic acid. The overexpression of COX-2 can cause an increase in prostaglandin $\mathrm{E}_{2}$ (PGE2) as a major metabolite product that promotes proliferation, inhibition of apoptosis, and angiogenesis [3, 4]. Excessive expression of COX-2 has been detected in several cases of tumors, one of them in the breast [5, 6]. Excessive expression of COX-2 in the human breast causes a larger tumor size, high degree of differentiation, and high proliferation [7-9]. The inhibition of COX-2 by a specific inhibitor will suppress the overexpression and delay the progression of cancers [10, 11]. Another 
mechanism for cancer suppression is a dual inhibition of COX-2 and Epidermal Growth Factor Receptor (EGFR), as shown by Ref [12].

Some COX-2 inhibitor compounds are available in the market, such as celecoxib, rofecoxib, and valdecoxib. Therefore, a new inhibitor that does not cause side effects are still needed. Some candidates for COX-2 inhibitors are found in soursop. Annonaceous acetogenin is a natural compound widely studied for its inhibitory activity against COX-2 [13]. Its toxicity mainly characterizes the biological activity of annonaceous acetogenin compounds to cancer cells and inhibitory effects on the mitochondrial complex I, which can reduce the production of ATP in cancer cells and eventually kill the cancer cells [14].

Soursop plants can be a drug for various diseases, e.g., anti-parasitic, anti-arthritic, anticonvulsant, anti-diabetic, anti-inflammatory, antioxidant, anti-hypertensive, gastro-protective, anti-hepatitis, anti-malaria, anti-hemorrhoids, and others [15-22]. In vitro studies show that active soursop compounds have anti-cancer activity against various cancer cell cultures $\quad[13$, 23-31]. Anti-tumor effects on soursop leaves are also reported in the in vivo study in 712dimethylbenzene anthracene (DMBA), which induced cell proliferation in rat's breast tissue. The protective effect against DNA damage caused by DMBA shows that oral administration of soursop leaves has a protective effect on the development of breast carcinogenesis and reduce the tumor mass $[23,32]$. This case is not only limited to in vitro and in vivo investigations. A case study of a 66-year-old woman with metastatic breast cancer reports that consumption of leaves boiled in water and Xeloda (a chemotherapy agent) results in the stabilization of the disease [33]. However, the side effects that occur due to chemotherapy are nausea, vomiting, diarrhea, stomatitis, alopecia, susceptibility to infection, thrombocytopenia, neuropathy, and myalgia are still exist $[34,35]$.

This research simulates the molecular interactions between active compounds of soursop and the COX-2 enzyme using molecular docking simulation. The docking performance or soursop's active compounds (Annonaceous acetogenin) will be compared to the docking performance of celecoxib as the standard ligand/comparative ligand to define their potential as an anti-breast cancer agent. The additional physicochemical and pharmacochemical analysis was also performed by utilizing the free web servers, such as molinspiration.com and Swiss ADME, to evaluate the compounds' drug-likeness to be developed into anti-breast-cancer agents. This research has limited our study by only performing a molecular docking simulation and physicochemical analysis. A further step, such as molecular dynamics simulation, to check the complex's binding integrity is our ongoing project.

\section{Materials and Methods}

\subsection{Preparation of receptor and ligand.}

The preparation of receptor and ligand structures is the first step to simulating molecular docking. The receptor used in this research is COX-2 from Protein Data Bank (PDB), deposited by [36] on the website https://www.rcsb.org/ with code 3LN1. The location of celecoxib can be used as a docking coordinate for test ligands on the targeted docking approach. The threedimensional structure of COX-2 was downloaded in PDB format, the added polar hydrogen atoms, and the addition of charge using AutoDock Tools software and saved in PDBQT format.

There are two types of ligand, the test ligand and the comparative or control ligand (a patented drug). Test ligands were active compounds of soursop, and the control ligand is celecoxib (see Figure 1). The reason for using celecoxib as a control ligand is because it is a 
COX-2 inhibitor that has been marketed in several countries and has been found attached in the active sites of COX-2 in the PDB database. The three-dimensional structure of test ligands was downloaded from the PubChem website at https://pubchem.ncbi.nlm.nih.gov/ in SDF format and converted into PDB format using Chimera 1.9 [37] before converted into PDBQT format using AutoDock Tools. The same step goes for the control ligand. After being separated from COX-2, celecoxib was saved in PDB format then converted to PDBQT format.

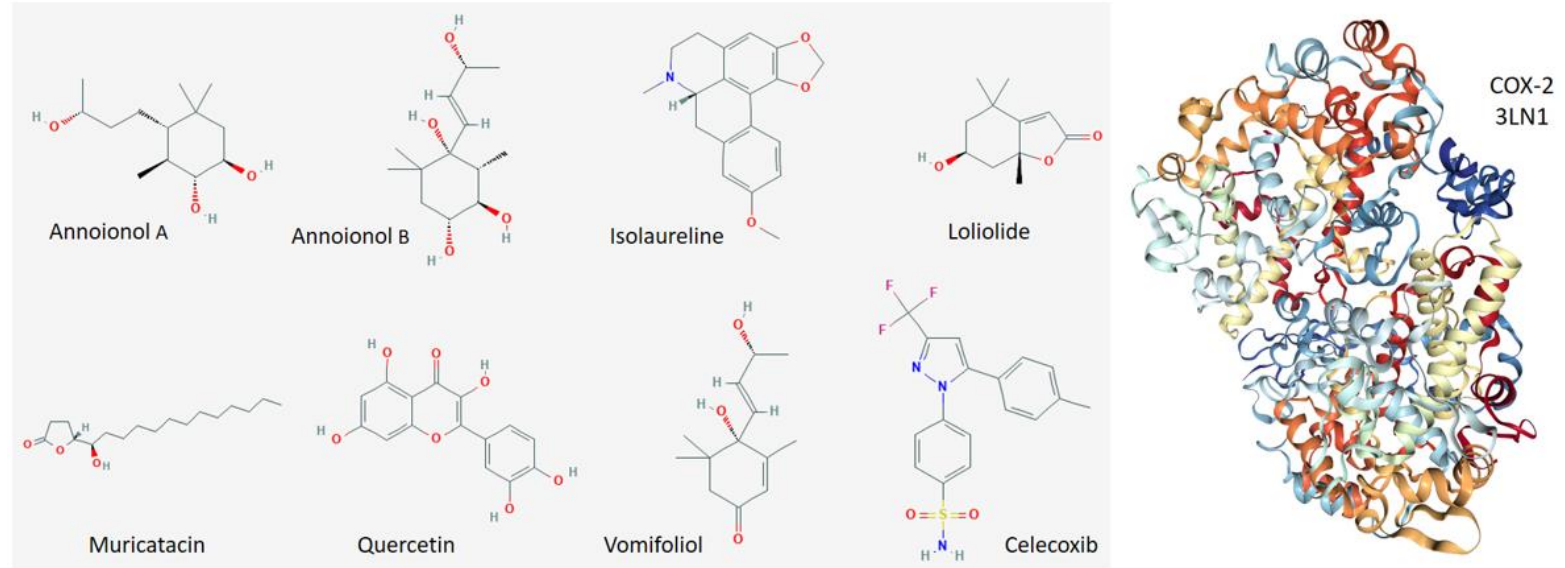

Figure 1. The chemical structure of the active compounds of soursop, including the control ligand (celecoxib) and the target protein (COX-2). Ligand structures were downloaded from https://pubchem.ncbi.nlm.nih.gov/, while the COX-2 structure was downloaded from https://www.rcsb.org/ with PDB code 3LN1. Note that figures are not to scale.

\subsection{Celecoxib validation as control ligand.}

Molecular docking simulation was performed by using Autodock Vina [38]. The validity of the docking program can be checked by performing the redocking procedure. This was done by redocking the celecoxib compound separated from COX-2 to the COX-2 enzyme itself in its active sites. As reported by [39], the active (binding) sites of COX-2 enzyme involved in the celecoxib-COX-2 complex are His75, Arg499, Ala502, Ile503, Gln178, Phe504, Trp373, Met508, Leu370, Gly512, and Ala513 [21]. Our validation (redocking) results showed the value of Gibbs free energy, $\Delta \mathrm{G}=-12.2 \mathrm{kcal} / \mathrm{mol}$. The occurrence of two interactions of the hydrogen atom of celecoxib with COX-2 and the amino acids involved in the redocking simulation are His75, Val102, Arg106, Gln178, Val335, Leu338, Ser339, Gly340, Tyr341, Trp373, Arg499, Ala502, Ile503, Met504, Val509, Gly512, Ala513, Ser516, Leu517. Those lists of amino acids will be used in defining the Similarity of active sites (SAS) of the tested ligands.

The results obtained after matching the location of the amino acids according to the literature [39] will form a new grid box with the coordinates center at $x=28.8269, y=-23.4389$, $z=-15.0943$; and with the grid box size of $\mathrm{x}=28.8383, \mathrm{y}=28.6639$, and $\mathrm{z}=31.2173 \AA$. These coordinates correspond to the location of the celecoxib that already exists in the COX-2 protein and will be used as a grid box reference in the docking simulation of the test ligand. This technique of selecting a specific site is commonly known as a targeted docking method.

\subsection{Molecular docking simulation and data analysis.}

Molecular docking is an effective computational approach to evaluating a ligand (compound) binding on a particular enzyme. A thermodynamics-based model complemented with optimization and statistical method produces the score function, which helps us determine 
a ligand's potential in inhibiting protein or enzyme for a particular purpose (inhibitor or regulator of a specific biochemistry pathway). Molecular docking of the active compounds of soursop was performed on the active sites of the COX-2 enzyme, as mentioned above. Each of the test ligand (the active compounds of soursop) was docked 20 times to get the best Gibbs free energy $(\Delta \mathrm{G})$. The molecular docking simulation was carried out using AutoDock Vina software. The final results in the form of the binding energy value/Gibbs free energy and the list of amino acids involved in that binding. The binding energy is evaluated intramolecularly from a non-bound state to a boundary conformation for each molecule separately (a protein first, then continued with the ligand), and then evaluated intermolecularly, bringing the two molecules together into bound complexes (protein and ligand). Analysis and visualization of the molecular interactions were done by using Chimera 1.9 software.

\section{Results and Discussion}

The Gibbs free energy indicates whether or not the ligand-enzyme complex is formed spontaneously. The more negative the value of $\Delta \mathrm{G}$, the stronger the ligand-enzyme binding that is formed. The molecular docking result is shown in Table 1. As the standard/control ligand, Celecoxib has a binding affinity $(\Delta \mathrm{G})$ of $-12.20 \mathrm{kcal} / \mathrm{mol}$. For the active compound of soursop, xylopine has the lowest Gibbs free energy as compared to other test ligands with $\Delta \mathrm{G}$ $=-11.2 \mathrm{kcal} / \mathrm{mol}$ and followed by annonamine $(-9.9 \mathrm{kcal} / \mathrm{mol})$ and epicatechin $(-9.8 \mathrm{kcal} / \mathrm{mol})$. This shows that in terms of Gibbs free energy, xylopine has the most potential to be developed as an anti-breast-cancer agent compared to other active compounds of soursop.

Table 1. Docking results.

\begin{tabular}{l|c|c|c} 
Label & Ligand & $\begin{array}{c}\Delta \mathbf{G} \\
(\mathbf{k c a l} / \mathbf{m o l})\end{array}$ & $\begin{array}{c}\text { Total Similarity of active } \\
\text { sites SAS (Percentage) }\end{array}$ \\
\hline LC & Celecoxib (Control ligand) & -12.2 & $100 \%$ \\
\hline L1 & Annoionol A & -7.1 & $70 \%$ \\
\hline L2 & Annoionol B & -7.1 & $74 \%$ \\
\hline L3 & Annonamine & -9.9 & $78 \%$ \\
\hline L4 & Epicatechin & -9.8 & $83 \%$ \\
\hline L5 & Isolaureline & -9.5 & $74 \%$ \\
\hline L6 & Loliolide & -6.8 & $52 \%$ \\
\hline L7 & Muricatacin & -7.1 & $74 \%$ \\
\hline L8 & Quercetin & -9.7 & $78 \%$ \\
\hline L9 & Vomifoliol & -7.3 & $78 \%$
\end{tabular}

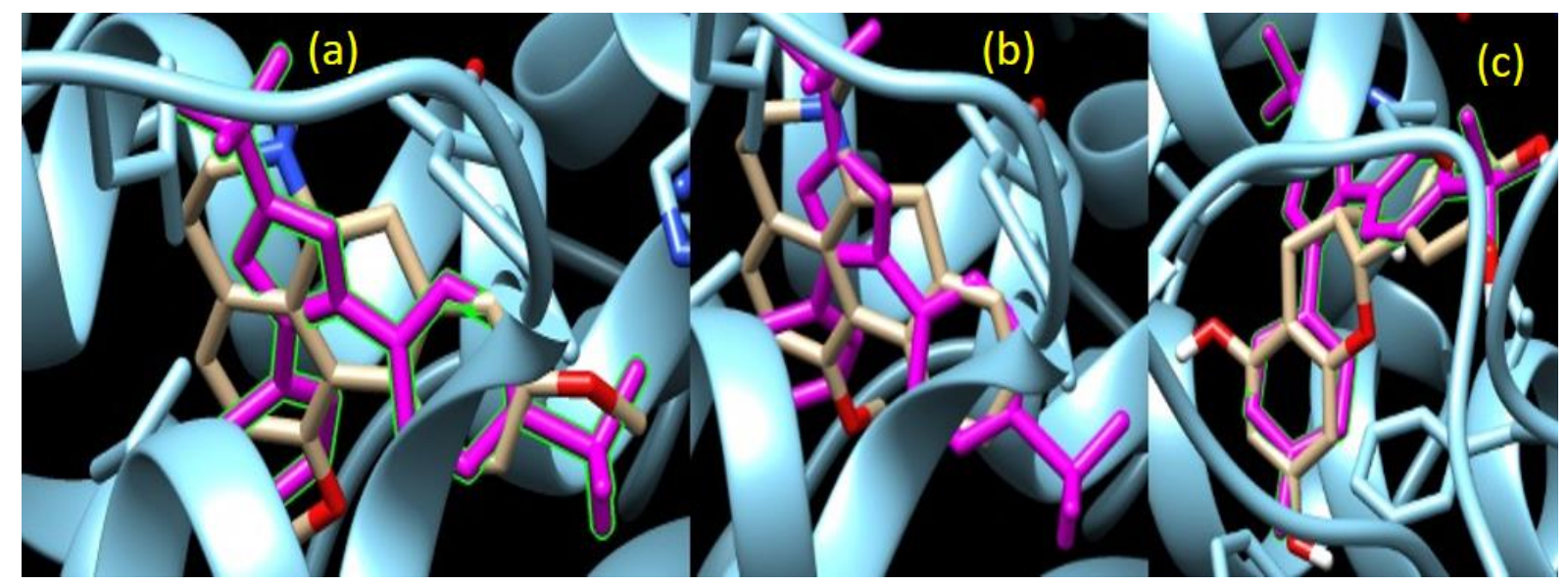

Figure 2. Comparison of docking sites of celecoxib (structure in magenta color) and the selected active compounds of soursop (structures in gold color) for (a) xylopine (b) annonamine (c) epicatechin. 
Even though its $\Delta \mathrm{G}$ is a bit weaker than celecoxib, but based on the ratio of binding energy to molecular size (molecular weight of celecoxib is $381.4 \mathrm{~g} / \mathrm{mol}$, and xylopine is 295.3 $\mathrm{g} / \mathrm{mol})$, xylopine has a better ratio $(0.038 \mathrm{kcal} / \mathrm{g})$ than celecoxib $(0.032 \mathrm{kcal} / \mathrm{g})$. This ratio shows that xylopine is more effective in inhibiting the active sites of COX-2 compares to celecoxib.

The comparison of binding sites of celecoxib and the selected ligands of soursop are depicted in Figure 2. The Similarity of the active site (SAS) illustrates how similar the test ligands' interaction to the control ligand. The comparison of each tested ligand's binding sites compared to the control ligand is shown in Figure 3. The yellow color indicates the amino acid involved in the ligand-receptor complex. The majority of test ligands are docked with a SAS percentage greater than $70 \%$. The highest SAS is shown by epicatechin with 19/23 residues or around $83 \%$, followed by annonamine, quercetin, and xylopine, which all have $78 \%$. Residues Val335, Leu338, Ser339, Trp373, Phe504, Val509, Gly512, Ala513, Ser516 always appear in ligand interactions with receptor so that these residues are predicted to play an important role in the binding site of COX-2.

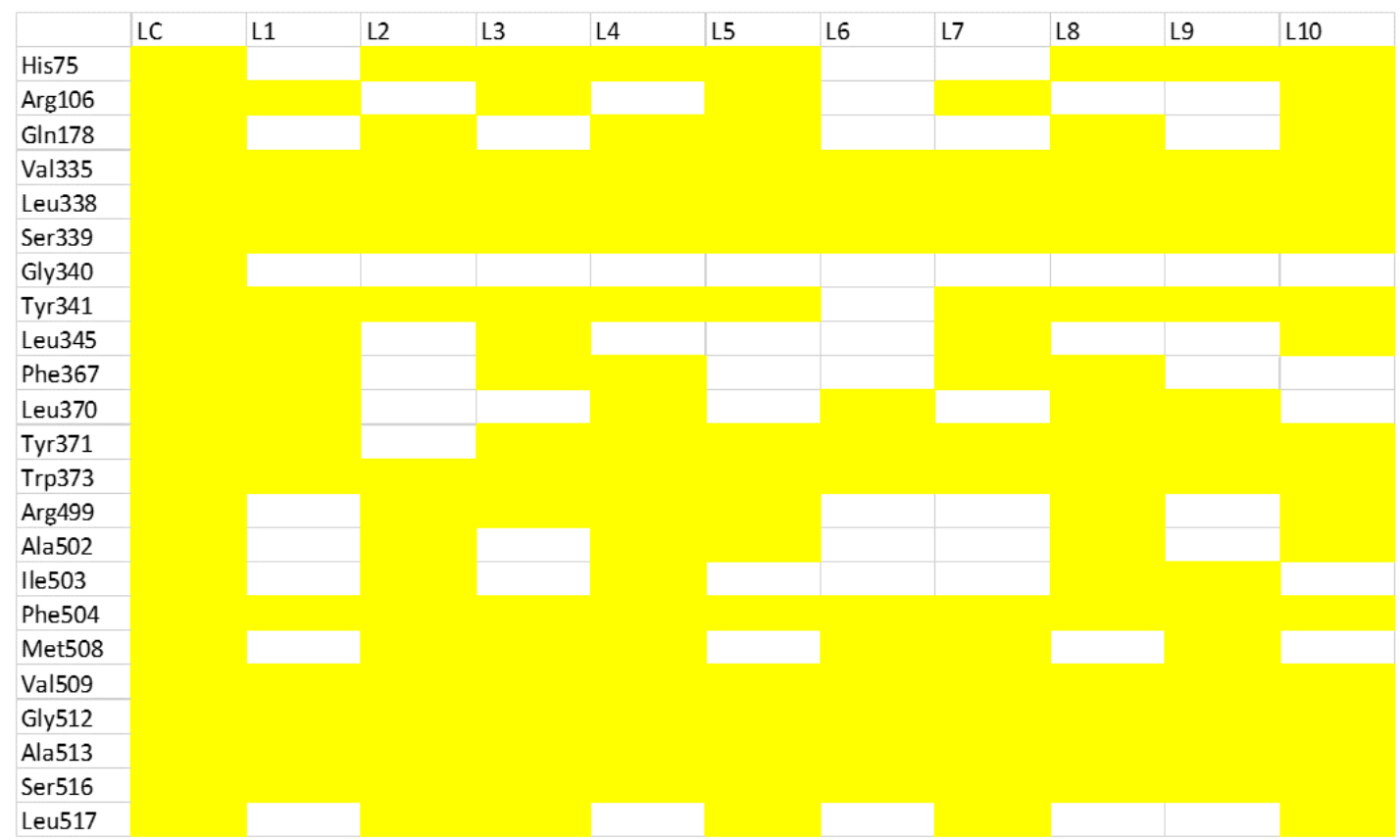

Figure 3. Comparison of the binding sites of each tested ligand as compared to the control ligand. The yellow color indicates the amino acid involved in the ligand-receptor complex. The label LC through L10 denotes the ligand's name following the first column of Table 1.

Xylopine, the best ligand performer based on the Gibbs free energy, has the SAS value of $78 \%$. This illustrates that xylopine is very easy to bind strongly to COX-2, but in a pocket that slightly off from the active sites of celecoxib. The active compound of soursop with the highest SAS is epicatechin (83\%), which has Gibbs free energy of $-9.8 \mathrm{kcal} / \mathrm{mol}$ and the binding effectivity of $0.034 \mathrm{kcal} / \mathrm{g}$ (still below xylopine but slightly better than celecoxib). Epicatechin has also been found to have potential as an anti-obesity agent, as reported by [40]. The worst performer of the active compound of soursop is loliolide. Its low Gibbs energy of $-6.8 \mathrm{kcal} / \mathrm{mol}$ and SAS value of $52 \%$.

The molecular property evaluation of the selected ligands is shown in Figure 4. In Figure 4, the molecular lipophilicity potential reveals that celecoxib is dominated by the hydrophobic potential as indicated by a blue-violet surface potential. Xylopine is also 
dominated by blue-violet surface potential. The domination of hydrophobic interaction explains why celecoxib and xylopine are deeply buried in the pocket of interaction with strong binding affinities compared to annonamine and epicatechin. The potential of xylopine and other annonacin and acetogenin compounds in inhibiting cancer progression has also been emphasized by Ref [41, 42]. Anonamine and epicatechin, on the other hand, are dominated by the yellow-orange surface potential, which indicates the domination of hydrophilic potential and tends to interact with the water molecule outside the binding pocket of the COX-2 enzyme.

The physicochemical and pharmacochemical evaluation of the selected ligands is very important in deciding the drug-likeness of a particular chemical compound to be developed into a potential drug. The physicochemical descriptor of ligands was computed by an online web server (SwissADME) [43]. Six properties must be evaluated, as shown in Table 2. The drug-likeness of the selected ligands is shown in a radar-like presentation in Figure 5. The physicochemical and pharmacochemical values of an ideal drug must lie within the hexagonal boundary region. All selected ligands have those properties mostly within the range of druglikeness values, except for epicatechin and celecoxib, which has saturation values below the limit of 0.25 ( 0.12 for celecoxib, and 0.20 for epicatechin). The solubility value, xylopine, annonamine, and epicatechin are classified as a soluble compound due to their value of Log $S$ (ESOL) between -4.0 to -2.0. Interestingly, celecoxib, which is the standard drug for COX-2 inhibition, is only classified as a moderately soluble compound with the value of $\log S$ (ESOL) of -4.49 . The strong binding of celecoxib on COX-2 enzyme might come from the ligand flexibility, where celecoxib has four rotational bonds. In contrast, the rest (xylopine, annonamine, and epicatechin) only have one rotational bond.

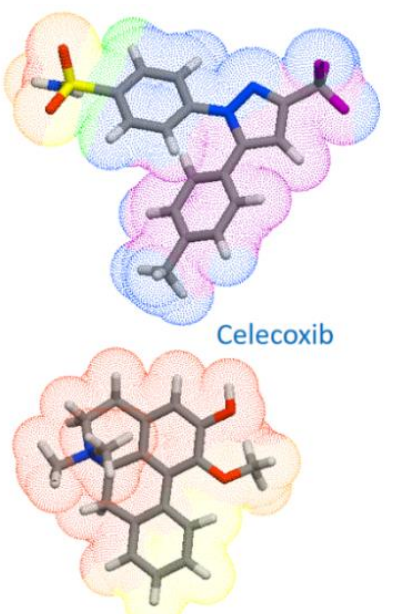

Annonamine

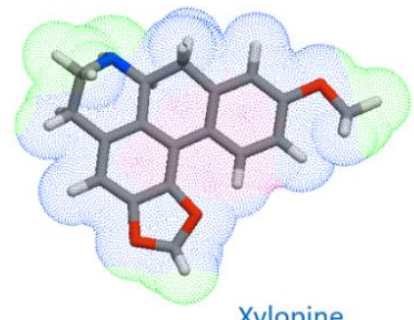

Xylopine

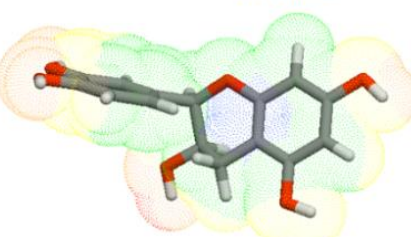

Epicatechin

Figure 4. The molecular lipophilicity potential (MLP) of the best-tested ligands. The hydrophobic surface is shown in blue-violet color, while the hydrophilic surface is indicated by yellow-orange color. Pictures were generated by Molinspiration Galaxy 3D Structure Generator v2018.01 beta (www.molinspiration.com).

Table 2. The Physicochemical descriptor of drug-likeness of the tested ligands.

\begin{tabular}{l|l|l|l|l|l} 
Properties & Drug-likeness values & Celecoxib & Xylopine & Annonamine & Epicatechin \\
\hline Lipophilicity & $-0.7<\mathrm{XLOGP} 3<+5.0$ & 3.40 & 2.80 & 3.12 & 0.36 \\
\hline Size & $150 \mathrm{~g} / \mathrm{mol}<\mathrm{MV}<500 \mathrm{~g} / \mathrm{mol}$ & $381.37 \mathrm{~g} / \mathrm{mol}$ & $295.33 \mathrm{~g} / \mathrm{mol}$ & $296.38 \mathrm{~g} / \mathrm{mol}$ & $290.27 \mathrm{~g} / \mathrm{mol}$ \\
\hline Polarity & $20 \AA^{2}<\mathrm{TPSA}<130 \AA^{2}$ & $89.36 \AA^{2}$ & $39.72 \AA^{2}$ & $29.46 \AA^{2}$ & $110.38 \AA^{2}$ \\
\hline Solubility & $0<\mathrm{Log} \mathrm{S}(\mathrm{ESOL})<6$ & -4.57 & -3.77 & -3.98 & -2.22 \\
\hline Saturation & $0.25<$ Fraction Csp3 $<1$ & 0.12 & 0.33 & 0.37 & 0.20 \\
\hline Flexibility & $0<$ Num rotatable bonds $<9$ & 4 & 1 & 1 & 1
\end{tabular}


In general, the efficacy potential of the active compounds of soursop in combating the progression of cancer (especially breast cancer) as discussed in various References [23, 25-27, 29-31, 41, 44] have been confirmed in this research, with xylopine turns out to be the most potent compound for an anti-breast-cancer agent. The drug-likeness of the active compounds of soursop, as reflected in the physicochemical descriptor in Table 2, shows safe and tolerable compounds for oral drug application and agrees with other researchers' results [45]. Further proof through the in vitro and in vivo research still needs to be done to validate this finding.

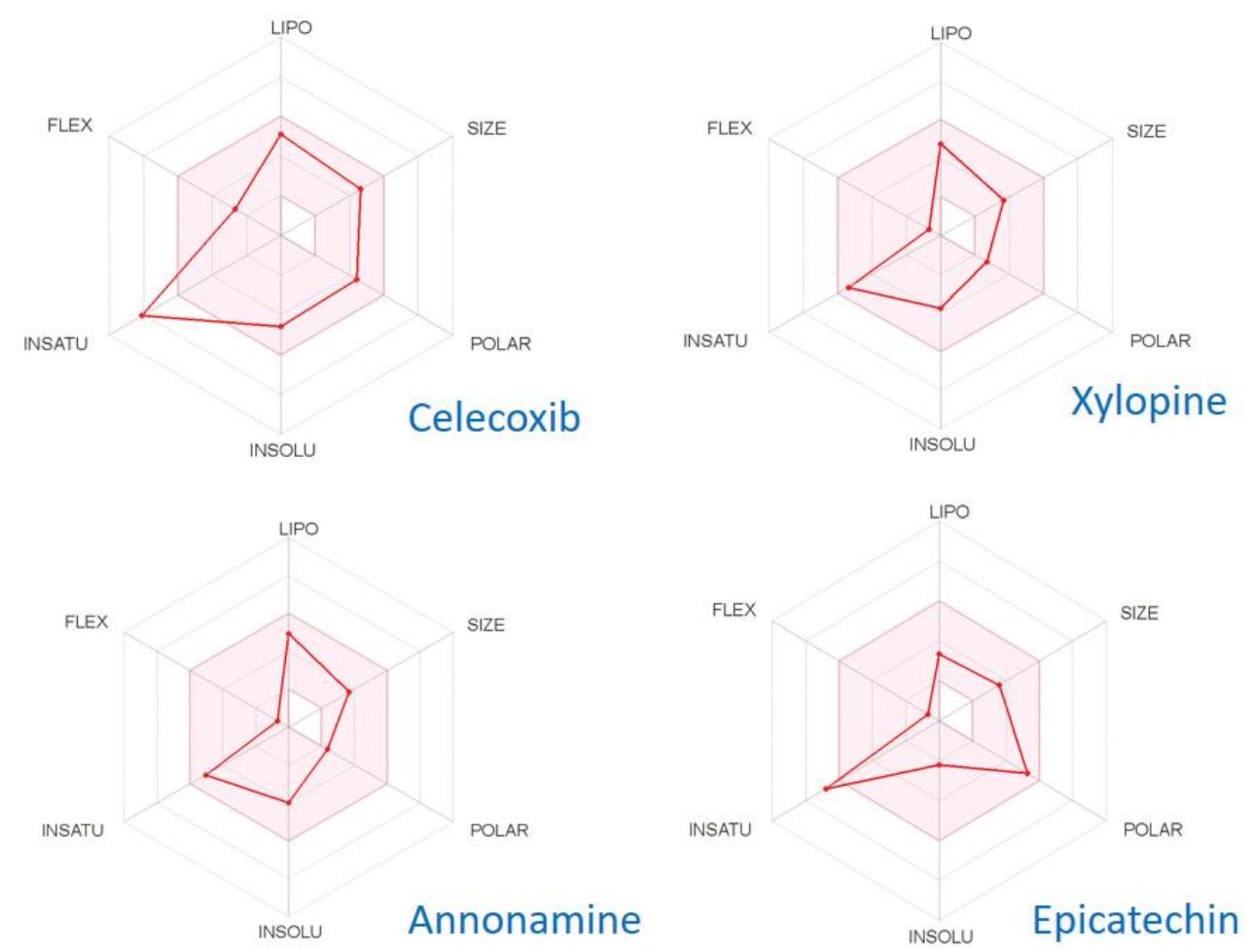

Figure 5. The radar-like representation of the drug-likeness of the tested ligands calculated by SwissADME, the online server database.

\section{Conclusions}

Molecular interaction and the physicochemical/pharmacochemical analysis of the active compounds of soursop (Annona muricata Linn) have been carried out in this research. The results show that the active compounds in soursop could play a role in inhibiting the work of the COX-2 enzyme. Based on that analysis, out of ten compounds tested, xylopine turns out to be the most potent inhibitors of COX-2 enzyme for an anti-breast-cancer agent, followed by annonamine, and epicatechin. A stronger binding affinity and better profile in the physicochemical/pharmacochemical descriptors compared to other tested ligands make xylopine a strong candidate to be developed as an anti-breast-cancer agent.

\section{Funding}

This research received no external funding.

\section{Acknowledgments}

The authors express their gratitude for the computational support from the Department of Physics, IPB University. 


\section{Conflicts of Interest}

\section{The authors declare no conflict of interest.}

\section{References}

1. The Global Cancer Observatory. Cancer Fact Sheet. World Heal. Organ. 2019.

2. World Health Organization. Indonesia Source GLOBOCAN 2018. Int. Agency Res. Cancer 2019.

3. Wu, S.; Huang, D.; Su, X.; Yan, H.; Ma, A.; Li, L.; Wu, J.; Sun, Z. The prostaglandin synthases, COX-2 and L-PGDS, mediate prostate hyperplasia induced by low-dose bisphenol A. Scientific Reports 2020, 10, 1 https://doi.org/10.1038/s41598-020-69809-y.

4. Williams, C.S.; Mann, M.; DuBois, R.N. The role of cyclooxygenases in inflammation, cancer, and development. Oncogene 1999, 18, 7908-7916, https://doi.org/10.1038/sj.onc.1203286.

5. Zelenay, S.; Van Der Veen, A.G.; Böttcher, J.P.; Snelgrove, K.J.; Rogers, N.; Acton, S.E.; Chakravarty, P.; Girotti, M.R.; Marais, R.; Quezada, S.A.; Sahai, E.; Soua, C.E. Cyclooxygenase-Dependent Tumor Growth through Evasion of Immunity. Cell 2015, 162, 1257-1270, https://doi.org/10.1016/j.cell.2015.08.015.

6. Harris, R.E.; Casto, B.C.; Harris, Z.M. Cyclooxygenase-2 and the Inflammogenesis of Breast Cancer. World J. Clin. Oncol. 2014, 5, 677-692, https://doi.org/10.5306/wjco.v5.i4.677.

7. Singh-Ranger, G.; Salhab, M.; Mokbel, K. The role of cyclooxygenase-2 in breast cancer: review. Breast Cancer Research and Treatment 2008, 109, 189-198, https://doi.org/10.1007/s10549-007-9641-5.

8. Singh, B.; Lucci, A. Role of Cyclooxygenase-2 in Breast Cancer. Journal of Surgical Research 2002, 108, 173-179, https://doi.org/10.1006/jsre.2002.6532.

9. Half, E.; Tang, X. M.; Gwyn, K.; Sahin, A.; Wathen, K.; Sinicrope, F.A. Cyclooxygenase-2 Expression in Human Breast Cancers and Adjacent Ductal Carcinoma in Situ. Cancer Res. 2002, 62, 1676-1681.

10. Zhang, Q.-L.; Zhang, J.; Xia, P.-F.; Peng, X.-J.; Li, H.-L.; Jin, H.; Li, Y.; Yang, J.; Zhao, L. Antiinflammatory activities of gentiopicroside against iNOS and COX-2 targets. Chinese Herbal Medicines 2019, 11, 108-112, https://doi.org/10.1016/j.chmed.2018.10.004.

11. Sobolewski, C.; Cerella, C.; Dicato, M.; Ghibelli, L.; Diederich, M. The Role of Cyclooxygenase-2 in Cell Proliferation and Cell Death in Human Malignancies. International Journal of Cell Biology 2010, 2010, https://doi.org/10.1155/2010/215158.

12. Tang, H.; Liu, Y.; Wang, C.; Zheng, H.; Chen, Y.; Liu, W.; Chen, X.; Zhang, J.; Chen, H.; Yang, Y.; Yang, J. Inhibition of COX-2 and EGFR by Melafolone Improves Anti-PD-1 Therapy through Vascular Normalization and PD-L1 Downregulation in Lung Cancer. Journal of Pharmacology and Experimental Therapeutics 2019, 368, 401-413, https://doi.org/10.1124/jpet.118.254359.

13. Sun, S.; Liu, J.; Kadouh, H.; Sun, X.; Zhou, K. Three new anti-proliferative Annonaceous acetogenins with mono-tetrahydrofuran ring from graviola fruit (Annona muricata). Bioorg Med Chem Lett 2014, 24, 27732776, https://doi.org/10.1016/j.bmcl.2014.03.099.

14. Moghadamtousi, S.Z.; Fadaeinasab, M.; Nikzad, S.; Mohan, G.; Ali, H.M.; Kadir, H.A. Annona muricata (Annonaceae): A Review of Its Traditional Uses, Isolated Acetogenins and Biological Activities. International Journal of Molecular Sciences 2015, 16, 15625-15658, https://doi.org/10.3390/ijms160715625.

15. Dash, S.; Kar, B.; Sahoo, N.; Pattnaik, G. Annonaine an Alkaloid from the Leaves of Custard Apple (Annona Squamosa): A Comprehensive Review on Its Phytochemicals and Pharmacological Activities. Asian Journal of Chemistry 2020, 32, 1824-1836, https://doi.org/10.14233/ajchem.2020.22696.

16. Okhale, S.; Akpan, E.; Fatokun, O.; Folashade, O.; Esievo, K.; Kunle, O. Annona senegalensis Persoon (Annonaceae): A review of its ethnomedicinal uses, biological activities and phytocompounds. J. Pharmacogn. Phytochem. 2016, 5, 211-219.

17. Patel, S.; Patel, J.K. A Review on a Miracle Fruits of Annona Muricata. J. Pharmacogn. Phytochem. 2016, 5, 137-148.

18. Coria-Téllez, A.V.; Montalvo-Gónzalez, E.; Yahia, E.M.; Obledo-Vázquez, E.N. Annona muricata: A comprehensive review on its traditional medicinal uses, phytochemicals, pharmacological activities, mechanisms of action and toxicity. Arabian Journal of Chemistry 2018, 11, 662-691, https://doi.org/10.1016/j.arabjc.2016.01.004.

19. Ismail, A.; Mohamed, M.; Kwei, Y.; Yin, K. Euphorbia Hirta Methanolic Extract Displays Potential Antioxidant Activity for the Development of Local Natural Products. Pharmacognosy Res. 2019, 11, 78-85, https://doi.org/10.4103/pr.pr_113_18.

20. Apriyanto, D.R.; Hartati, S.; Dewi, B.E.; Aoki-Utsubo, C.; Hotta, H. In Vitro study of Garcinia celebica L. Stem Barks against Hepatitis C virus and Hepatocellular Carcinoma. Journal of Physics: Conference Series 2019, 1360, https://doi.org/10.1088/1742-6596/1360/1/012027.

21. Dadzie, I.; Avorgbedo, S.A.; Appiah-Opong, R.; Cudjoe, O. Cytotoxic and Antioxidant Effects of Antimalarial Herbal Mixtures. Int. J. Microbiol. 2020, 2020, https://doi.org/10.1155/2020/8645691. 
22. Ayun, N.Q.; Kusmardi; Nurhuda; Elya, B. Anti-Inflammation of Soursop Leaves (Annona Muricata 1.) against Hemorrhoids in Mice Induced by Croton Oil. Pharmacogn. J. 2020, 12, 784-792, https://doi.org/10.5530/pj.2020.12.112.

23. Minari, J. B.; Okeke, U. Chemopreventive Effect of Annona Muricata on DMBA-Induced Cell Proliferation in the Breast Tissues of Female Albino Mice. Egypt. J. Med. Hum. Genet. 2014, 15 327-334, https://doi.org/10.1016/j.ejmhg.2014.05.001.

24. Sulistyoningrum, E.; Rachmani, E.P.N.; Baroroh, H.N.; Rujito, L. Annona Muricata Leaves Extract Reduce Proliferative Indexes and Improve Histological Changes in Rat's Breast Cancer. J. Appl. Pharm. Sci. 2017, 7, https://doi.org/10.7324/JAPS.2017.70120.

25. Kim, J.Y.; Dao, T.T.P.; Song, K.; Park, S.B.; Jang, H.; Park, M.K.; Gan, S.U.; Kim, Y.S. Annona Muricata Leaf Extract Triggered Intrinsic Apoptotic Pathway to Attenuate Cancerous Features of Triple Negative Breast Cancer MDA-MB-231 Cells. Evidence-based Complement. Altern. Med. 2018, 2018, https://doi.org/10.1155/2018/7972916.

26. Pieme, A.A.; Kumar, G.G.; Dongmo, S.S.; Moukette, M.M.; Boyoum, F.F.; Ngogang, Y.Y.; Saxena, K.K. Antiproliferative Activity and Induction of Apoptosis by Annona Muricata (Annonaceae) Extract on Human Cancer Cells. BMC Complement. Altern. Med. 2014, 14, https://doi.org/10.1186/1472-6882-14-516.

27. Yajid, A.I.; Ab Rahman, H.S.; Wong, M.P.K.; Wan Zain, W.Z. Potential Benefits of Annona Muricata in Combating Cancer: A Review. Malaysian Journal of Medical Sciences 2018, 5-15, https://doi.org/10.21315/mjms2018.25.1.2.

28. Syed Najmuddin, S.U.F.; Romli, M.F.; Hamid, M.; Alitheen, N.B.; Abd Rahman, N.M.A.N. Anti-Cancer Effect of Annona Muricata Linn Leaves Crude Extract (AMCE) on Breast Cancer Cell Line. BMC Complement. Altern. Med. 2016, 16, https://doi.org/10.1186/s12906-016-1290-y.

29. Prasad, S.K.; Varsha, V.; Devananda, D. Anti-Cancer Properties of Annona Muricata (L.): A Review. Med. Plants 2019, 11, 123-134, https://doi.org/10.5958/0975-6892.2019.00016.9.

30. Cassé, C. Molecular Mechanisms of Annona Muricata Anti-Proliferative/Anti-Cancer Properties. Biomed. Genet. Genomics, 2018, 4 (1). https://doi.org/10.15761/bgg.1000138.

31. Daddiouaissa, D.; Amid, A.; Kabbashi, N.A.; Fuad, F.A.A.; Elnour, A.A.M.; Epandy, M.A.K.M.S. Antiproliferative Activity of Ionic Liquid-Graviola Fruit Extract against Human Breast Cancer (MCF-7) Cell Lines Using Flow Cytometry Techniques. J. Ethnopharmacol. 2019, 236, 466-473, https://doi.org/10.1016/j.jep.2019.03.003.

32. Ibrahim, A.Y.; Youness, E.R.; Mahmoud, M.G.; Asker, M.S.; El-Newary, S.A. Acidic Exopolysaccharide Produced from Marine Bacillus Amyloliquefaciens 3MS 2017 for the Protection and Treatment of Breast Cancer. Breast Cancer Basic Clin. Res. 2020, 14, https://doi.org/10.1177/1178223420902075.

33. Hansra, D.M.; Silva, O.; Mehta, A.; Ahn, E. Patient with Metastatic Breast Cancer Achieves Stable Disease for 5 Years on Graviola and Xeloda after Progressing on Multiple Lines of Therapy. Adv. Breast Cancer Res. 2014, 03, 84-87, https://doi.org/10.4236/abcr.2014.33012.

34. Partridge, A.H.; Burstein, H.J.; Winer, E.P. Side Effects of Chemotherapy and Combined Chemohormonal Therapy in Women with Early-Stage Breast Cancer. Journal of the National Cancer Institute. Monographs. 2001, pp 135-142. https://doi.org/10.1093/oxfordjournals.jncimonographs.a003451.

35. Lemanne, D.; Maizes, V. Advising Women Undergoing Treatment for Breast Cancer: A Narrative Review. Journal of Alternative and Complementary Medicine 2018, 902-909, https://doi.org/10.1089/acm.2018.0150.

36. Wang, J.L.; Limburg, D.; Graneto, M.J.; Springer, J.; Hamper, J.R.B.; Liao, S.; Pawlitz, J.L.; Kurumbail, R.G.; Maziasz, T.; Talley, J.J.; Kiefer, J.R.; Carter, J. The novel benzopyran class of selective cyclooxygenase-2 inhibitors. Part 2: The second clinical candidate having a shorter and favorable human half-life. Bioorg Med Chem Lett 2010, 20, 7159-7163, https://doi.org/10.1016/j.bmcl.2010.07.054.

37. Pettersen, E.F.; Goddard, T.D.; Huang, C.C.; Couch, G.S.; Greenblatt, D.M.; Meng, E.C.; Ferrin, T.E. UCSF Chimera - A Visualization System for Exploratory Research and Analysis. J. Comput. Chem. 2004, 25, 1605-1612.

38. Trott, O.; Olson, A.J. AutoDock Vina: Improving the Speed and Accuracy of Docking with a New Scoring Function, Efficient Optimization. J. Comput. Chem. 2009, 31, 455-61, https://doi.org/10.1002/jcc.21334.

39. Razzaghi-Asl, N.; Mirzayi, S.; Mahnam, K.; Sepehri, S. Identification of COX-2 Inhibitors via StructureBased Virtual Screening and Molecular Dynamics Simulation. J. Mol. Graph. Model. 2018, 83, 138-152, https://doi.org/10.1016/j.jmgm.2018.05.010.

40. Sumaryada, T.; Simamora, R.E.M.; Ambarsari, L. Docking Evaluation of Catechin and Its Derivatives on Fat Mass and Obesity-Associated (FTO) Protein for Anti-Obesity Agent. J. Appl. Pharm. Sci. 2018, 8, 063-068, https://doi.org/10.7324/JAPS.2018.8810.

41. Abdul Wahab, S.M.; Jantan, I.; Haque, M.A.; Arshad, L. Exploring the Leaves of Annona muricata L. as a Source of Potential Anti-inflammatory and Anticancer Agents. Frontiers in Pharmacology 2018, 9, https://doi.org/10.3389/fphar.2018.00661.

42. Roduan, M.R.; Hamid, R.A.; Cheah, Y.K.; Mohtarrudin, N. Cytotoxicity, Antitumor-Promoting and Antioxidant Activities of Annona Muricata in Vitro. J. Herb. Med. 2019, 15, https://doi.org/10.1016/j.hermed.2018.04.004. 
43. Daina, A.; Michielin, O.; Zoete, V. SwissADME: A Free Web Tool to Evaluate Pharmacokinetics, DrugLikeness and Medicinal Chemistry Friendliness of Small Molecules. Sci. Rep. 2017, 7, https://doi.org/10.1038/srep42717.

44. Wang, Y.T.; Yang, C.H.; Huang, T.Y.; Tai, M.H.; Sie, R.H.; Shaw, J.F. Cytotoxic Effects of Chlorophyllides in Ethanol Crude Extracts from Plant Leaves. Evidence-based Complement. Altern. Med. 2019, 2019, https://doi.org/10.1155/2019/9494328.

45. Chan, W.J.J.; McLachlan, A.J.; Hanrahan, J.R.; Harnett, J.E. The Safety and Tolerability of Annona Muricata Leaf Extract: A Systematic Review. Journal of Pharmacy and Pharmacology 2020, 1-16, https://doi.org/10.1111/jphp.13182. 